\title{
Analysis on the Value of Cultural Tourism Resources Development in Pingxiang Spring Gong
}

\author{
Yeqin Peng \\ Academy of Arts of Pingxiang University,Pingxiang City,Jiangxi Province.China
}

Keywords: Pingxiang spring gong; Intangible cultural heritage; Cultural tourism

\begin{abstract}
If the fresh blood of Pingxiang Spring gong culture tourism resources is injected into the ranks of the development and protection of tourism industry, it not only expands the scope of tourism resources, but also helps the sustainable development of tourism industry. At the same time, it promotes the cultural connotation of local folk art and facilitates the successful transformation of cultural resources into tourism products. Further, it can not only make folk tourism in the operation of the process of continuous value-added development, but also conducive to promoting local economic and cultural common prosperity and development.
\end{abstract}

\section{Introduction}

With the rapid development of economy and the improvement of people's living standard and cultural level, people's demands for spiritual culture are getting higher and higher after the material level has been satisfied [1]. August 21, 2014, the State Council issued "on the promotion of tourism reform and development of a number of opinions". It puts forward specific requirements from such aspects as setting up scientific view of tourism, strengthening the power of tourism development, expanding the space for tourism development, optimizing the environment for tourism development, and improving the tourism development policy [2, 3]. In order to benefit in the fierce tourism environment, we should not only in the selection and construction of tourism products to highlight the special and culture, but also should develop and tap the local related cultural heritage, artistic charm, strong distinctive cultural products, and combined with the tourism resources.

Through the query of "Jiangxi intangible cultural heritage digital museum", Pingxiang spring gong belongs to the Pingxiang region "non heritage" in the most typical and the most representative of a variety of quyi [5]. It is with the most "intangible cultural heritage" traditional folk art. It also appeared in "professional artist loss" and "bearing industry," traditional music artists dating "lost", "composing barren" and "shortage of funds" and "limited venues" and "audience narrow" and many other problems.

Therefore, if the local folk culture and local folk art as attractions by creating the corresponding folk operas atmosphere and its use of derivatives and folk tourism and tourism combined the new "marriage" mode. This model will enable this traditional culture to survive in a rapidly changing society. Moreover, this model can maximize the rapid development of China's tourism industry. Not only it can create local characteristics of traditional folk art culture brand, but also can promote the development of local cultural tourism industry. For Pingxiang spring gong cultural tourism road to find a new and more relevant to contemporary social development and people's aesthetic requirements and aesthetic habits, this paper will talk about a few view from the current situation, Pingxiang spring gong intangible cultural tourism resources development and utilization of cultural heritage value.

\section{The status quo of cultural tourism resources of Pingxiang spring gong}

The status of Pingxiang spring gong

Pingxiang spring gong is also known as playing spring gong. It is a very colloquial rap style, popular in Jiangxi Province Pingxiang and Yichun, Wanzai and other cities and counties in Hunan 
Province, Liling, Liuyang and other surrounding areas. Pingxiang spring gong ultimately formed a comprehensive variety of folk art by using Pingxiang dialect, combined with music, dance, performance, literature [6, 7]. Its artistic style has many rich local characteristics, which cover the social change, folk customs, aesthetic fun and other cultural information.

At present, Pingxiang spring gong's performance is different from the past "walking village", "see praise" and other traditional forms [8]. Especially the "spring gong Yong king" Kaiquan teacher to the inheritance and development of traditional music, singing and acting in the form of innovation and the cultivation of talents singing have made outstanding contributions. However, under the impact of the current rapid economic development and cultural diversity, the traditional Chinese folk songs are squeezed into the space for survival and development, resulting in fewer and fewer audiences. In addition, the traditional folk songs have no fixed performing places, performing artists aged, inheriting artists' faults, and the development of repertoire is slow. In particular, the performing forms of Pingxiang spring gong are relatively old, and can not meet the rapid changing public aesthetic requirements in the new period, which has caused the severe development of the current spring gong in Pingxiang. Therefore, the development of the intangible cultural heritage of Pingxiang spring gong cultural tourism industry is not only to meet the needs of social development and economic development, but also to meet the needs of the people, the spirit of aesthetic and entertainment.

\section{Analysis of the status of opera tourism promotion throughout the country}

The opera tourism is a kind of cultural tourism which attracts tourists by creating the opera atmosphere and creating the cultural landscape of opera [9]. Su Song country built Huangmei opera culture theme park. The overall effect is based on Huang Mei Opera as the theme of cultural elements, set tourism viewing, knowledge appreciation, leisure and enjoy in one of the new theme of cultural park. Guilin in 2009 had built the Kesai Guilin Yanshan animation Opera culture industry park. It is the first domestic animation and Chinese representative opera combination and fully show the opera, architecture, food culture of the industrial park. The project intends to display animation opera culture as a leader. In the foundation of building the enthusiastic and passionate happy animation entertainment atmosphere, , development and production of animation derivative products, it stimulates the development and production of animation derivative products with the domestic outstanding plays as the carrier. Additionally, it also stimulates the implementation of industrial agglomeration and meet the surrounding regional service industry and business needs. Finally, a high-end cultural and recreational industrial park integrating cultural tourism, performing arts, teaching research, art training, art production, processing, leisure, entertainment, catering and other functions has been built. Further, the Chengdu Opera Center launched "Hibiscus quintessence" tourism performing arts projects. All of these are a successful example of the successful use of Chinese operas boost local tourism.

\section{The status quo of local tourism resources in Pingxiang}

Pingxiang City is located in the west of Jiangxi Province, and Hunan Province. As the leading cities, it is said "Hunan and Jiangxi thoroughfare" and "Wu Chu throat" [10]. It is the source of the Chinese workers movement and autumn harvest uprising source in the history. So it also has been "a hundred years coal." Pingxiang is located in the subtropical monsoon climate zone and it is a subtropical monsoon humid climate type. Most of the tourism resources in Pingxiang are mainly natural scenery, such as martial arts mountain, Nie Longdong, Daping Mountain, Moon Lake Scenic Area. In addition, Pingxiang has the natural history and Humanities of Yangqi Mountain Scenic area. The natural pastoral scenery of the main leisure agricultural tourism scenic area and the Luxi Mashan happy village "has just opened in Xian Feng Sambo" leisure agriculture garden light. Take the agricultural development project as the main part of Mao Jia Wan Culture Village scenic spot. Set business, leisure and entertainment as one of the integrated tourist attractions, Anyuan film and television city. In the historical and cultural site, the Anyuan coal miners' Club akayama Shidongkou King Xuan of Nuo temple and so on. These scenic spots are mainly based on the "look" mode of tourism, but less popular folk culture experience tourism form in Pingxiang. Therefore, in order to promote the development of Pingxiang tourism industry, we will use the Pingxiang local opera cultural resources. The formation of new opera cultural tourism industry is to promote the success of 
the tourism industry in Pingxiang upgrade. It is an important means to boost the sustainable development of tourism resources.

\section{Development and utilization value of cultural tourism resources in Pingxiang spring gong \\ SWOT analysis of tourism resources Pingxiang spring gong}

In order to better understand the status quo of the tourism resources of Pingxiang spring gong, this paper designed a questionnaire for Pingxiang spring gongs. Accumulated a total of 50 issued, to recover 50 copies. The questionnaire survey object were randomly selected Pingxiang local residents. The following is the survey data statistics:

Questionnaire for exploitation and utilization of tourist resources in Pingxiang spring gong.

Q1. Do you know the Pingxiang spring Gong?

Know (\%) don't know (\%) as if you have heard the name (\%)

Q2. Do you know that Pingxiang spring gong is a national intangible cultural heritage?

Know (36\%) do not know (54\%) seem to hear (10\%)

Q3. Have you heard of Yong Kaiquan?

Know (20\%) do not know (50\%) seem to have heard the name (30\%)

Q4. Do you like Pingxiang spring Gong?

Like (35\%) do not like (35\%) do not feel (30\%)

Q5. What do you think of the prospects of the Pingxiang spring gong?

Very good (40\%) general (20\%) is not easy to say (22\%) very bad (18\%)

Q6. Have you ever heard of opera tours, folk art tours and folk culture tours?

Know (30\%) do not know (35\%), seem to hear (35\%)

Q7. What do you think about the attraction of Pingxiang spring gong cultural tourism?

Good (54\%) general (20\%) to (20\%) - (6\%) is not attractive

Q8. What kind of promotional activities do you know about the local government on Pingxiang spring gong?

Q9. What do you think of Pingxiang's local tourism industry?

Q10. Can you make some suggestions for Pingxiang Spring gong?

The questionnaire survey shows that the current local people are not comprehensive to the knowledge of Pingxiang Spring gong. The survey shows that $54 \%$ of respondents do not know what is Pingxiang spring gong. The local government did to Pingxiang spring gong promotional activities are also poorly understood. But the survey shows that the overall development of the local tourism industry through the cultural media through the Pingxiang Spring gong and the future trends are more optimistic.

\section{"Non heritage" needs protection}

Since 2003, China's State Council announced the first batch of national intangible cultural heritage list. Then the country's intangible cultural heritage museum, exhibition hall, folk museum, training and other fields have been completed. These measures are to "non heritage" with the foundation Sexual protection. However, for our country at present, the living environment, the protection status and the most important inheritance of the intangible cultural heritage of various ethnic groups are still worrying.

In June 7, 2008, the "Pingxiang spring Gong" was listed as the second batch of national intangible cultural heritage and folk art list with the approval of the state council. "Non heritage" representative inheritors face aging trend, Yong Kaiquan teacher made outstanding contributions in the inheritance and development of reform and innovation of Pingxiang spring gong. In succession, Peng Liping, Yi Guohua, Huang Shaohui and other outstanding successors have been trained. But at the moment, there are still a few creators and performers, and a new generation of young people has been hampered by personal interests, money, and lack of a solid security system. Similarly, the lack of professional theoretical research personnel, to protect the backward basic theory research and practice of discipline system construction, protection of intangible cultural heritage project is also facing some academic bottlenecks. These problems are restricting the inheritance and development of 
Pingxiang spring gong.

\section{Artistic humanistic values and propagating local cultural values}

Pingxiang spring gong value is determined by its own nature. Because of its music, dance, performance, literature and other integrated form of artistic expression, it is Pingxiang folk art representatives with strong local characteristics.

Group spring gong, "Like Ping City" represented by Yong Hong and Peng Liping. It is a modern performance of modern Gong Song featuring the local customs and customs, folk culture, arts and Humanities and natural scenery in Pingxiang.

"Like Ping City" using humorous relaxed music tone from first to last, with the Pingxiang local dialect, the content of folk tales, such as field leads to the "three Hou Temple", "cross Dragon Temple", "Jinshan Temple", "Yang Qishan" and "Hoshakuji", "Wugong Mountain", "evil cave" and "Shidongkou Nuo Temple" and other natural and cultural landscape of religion.

Pingxiang celebrities list of emperor Qian Long appreciated the "Jiangxi talent" Liu Fenggao. Modern poets, scholars and reformists thinkers of Wen Tingshi. Chinese, co-founder of the Communist Party of the Communist Party of China one of the early leaders of Zhang Guotao. Former minister of education Liu Bin. Chinese academy of sciences Wu Xuezhou, Jane aquatic, Chen Shupeng. Music influential Yu Yixuan, revolutionary Wu Yunduo Huang Haihuai and so on. The history of the red list of Anyuan mine workers' movement site, referred to the geographical position of Pingxiang close to the Changsha Zhuzhou Xiangtan, docking Chang Zhu Min, Jiangxi is opening up the West gate. The whole song "like Ping City" is almost a name card to the folk traditional folk culture as a medium to promote Pingxiang local cultural values, in closely around Pingxiang spring gong traditional folk art performances at the same time. It also reflects its aesthetic characteristics and regional characteristics. Through its unique cultural and artistic charm, Pingxiang spring gong can become more people to understand Pingxiang, Pingxiang folk traditional culture and regional tourism culture.

\section{To promote the upgrading of local cultural tourism}

As early as 2005, the city put forward from the resource-exhausted cities to the tourism city transformation and development. In March 17, 2008, mining more than 100 years, China's famous old industrial base-Jiangxi Pingxiang was officially listed as China's one of the first 12 resource-exhausted cities. Facing the so severe test, Pingxiang municipal government is to take a number of measures to pay a great effort to transform the city, pollution control, building the park, financial foreign investment, Xing economy. It also gradually establish the cultural and ecological tourism industry to upgrade the stage of development and upgrading of the stage.

That the cultural resources of Pingxiang spring gong cultural tourism resources into the city's key tourism industry development and protection of the ranks expand the scope of tourism resources. And it also conducive to the sustainable development of tourism industry. It not only to enhance the local folk art and cultural connotation, but also conducive to the successful transformation of cultural resources into tourism products. Further, it can not only make the folk tourism in the course of operation increment development, but also conducive to the promotion of local economic and cultural development and prosperity.

\section{The value of economic benefits}

The development of Pingxiang spring gong cultural tourism resources is an important way to create high-end cultural tourism products. The development of cultural tourism resources must know how to accurately grasp its own cultural characteristics and market needs fit point. Targeted consumer groups must have some attraction. Not only for tourism development and utilization, but also to produce economic value. In addition, the development of Pingxiang Spring gong cultural tourism resources can promote local food, shelter, travel, shopping, entertainment, and further accelerate the construction of local infrastructure and enhance investment. Through the government's support policy, coupled with the creative cultural industry, it can provide more employment opportunities to the local people. Therefore, a large number of industries, such as tourism, construction, transportation, communications, services, transportation, catering, food, culture and education, are of great and 
far-reaching significance to the economic development of the Pingxiang region.

\section{Summary}

China's folk opera variety has a high and rich cultural connotation. The combination of tourism and tourism reform model can promote the development needs of the local tourism economy. It can promote the sustainable development of social-economic-ecological-cultural chain while maximizing the benefits of tourism industry. Therefore, this paper uses the folk art as an important cultural carrier to build a business marketing model. This model has a special and far-reaching significance for the rich people's spiritual life.

\section{Acknowledgements}

This work was supported by "Research on the intangible cultural heritage of Jiangxi Province Pingxiang spring gong investigation and music research" (Jiangxi Province soft science research project, project number: 20161BBA10026), the type of project: general project; Peng Yeqin as the first host.

\section{References}

[1] Where China meets Southeast Asia: social and cultural change in the border regions[M]. Institute of Southeast Asian Studies, 2000.

[2] LIU Y, JIA Y, SHI L. Evaluation of Socioeconomic Adaptability of Freeway Based on DEA Model [J][J]. Journal of Beijing Jiaotong University, 2007, 3: 000.

[3] Rioux Y L. Marketing the revolution: Tourism, landscape and ideology in China[D]. University of Colorado at Boulder, 2007.

[4] Yang S W. Being Aboriginal and Taiwanese in the Pursuit of Community Well-Being: Examining the Janus-Face of Public Health Among Bunun Peoples[J]. 2013.

[5] ZHANG Y, ZHAO X, TIAN J, et al. Heterosis of photosynthetic characteristics in Brassica napus L[J]. Journal of Northwest A \& F University (Natural Science Edition), 2013, 8: 008.

[6] Perry E J. Studying Chinese politics: farewell to revolution?[J]. The China Journal, 2007 (57): $1-22$.

[7] Xie T. Sprouting from Fissures: Pluralizing the Conceptions of China[J]. 2014.

[8] Ye Z. Big is modern: the making of Wuhan as a Mega-City in early twentieth century China, 1889-1957[J]. 2010.

[9] Schäfer D. Inscribing the Artifact and Inspiring Trust: The Changing Role of Markings in the Ming Era[J]. East Asian Science, Technology and Society, 2011, 5(2): 239-265.

[10] Brazil M. The Darkest Red Corner: Chinese Communist Intelligence and Its Place in the Party 1926-1945[J]. 2013. 